\title{
Urban Elderly Re-employment Current Situation and Countermeasures: An Analysis for China
}

\author{
Hong Gong ${ }^{1,2, *}$, Wenxiao Sun ${ }^{1}$, Yan Luo ${ }^{1}$ \\ ${ }^{1}$ Economics and Management School, Wuhan University, Wuhan, China \\ ${ }^{2}$ Research Center for China Industry-University-Research Institute Collaboration of Wuhan University, Wuhan, China
}

Copyright (C) 2015 by authors, all rights reserved. Authors agree that this article remain permanently open access under the terms of the Creative Commons Attribution License 4.0 International License

\begin{abstract}
Currently, the rapid population aging has posed a series of challenges for economic and social development in China. Facing with these problems, the Chinese government planned to formulate policies to progressive delay the retirement age, and regarded the "positive response to population aging" as one of the long-term development strategy. But in reality, with China's per capita life expectancy and human capital cycle "double extended", "old before getting rich" makes re-employment of the elderly population become very urgent. Based on China's current rapid population aging, this paper analyzed the current situation of China's re-employment of the elderly population, and proposed some effective countermeasures to support elderly re-employment.
\end{abstract}

Keywords Rapidly Aging, Re-employment Policy, Urban Elderly

\section{Introduction}

At present, the rapid population aging has posed a serious challenge for China's economic and social development. In recent years, the Chinese government began to study the policies to progressive delay the retirement age. As the basis for the implementation of the delayed retirement age policy, urban elderly re-employment has become one of the fundamental problems of aging population. Despite the government's advocate for elderly re-employment, because of the retirement age limit and the lack of a clear policy, there is a series of "hidden employment" phenomenon in the elderly re-employment, and it's difficult to protect the re-employment rights. Therefore, based on the actual situation of China, building effective re-employment policies has become one of the key issues of responding to the aging population's challenges.

\section{Literature Review}

Internationally, researchers mainly studied the elderly re-employment problems from the perspective of "active aging" and "productive aging". Walker (2005) pointed out that "active aging" is a strategy with good economic sense, it responds to the aging challenges, expands employment, and improves the life quality of old people. Nancy (2009) further believed that the productive participation of older persons including work, voluntary service, take care of their grandchildren, and such participation can generate multiple positive effects, like keeping old people healthy, alleviating the economic pressures caused by the aging population(Burnette, 2011; Guangzong Mu, 2011; Yuan Ren, 2013). But Leland and Elliott (2012) found that "productive aging" is to create more opportunities and choices for the elderly, encouraging them to play a valuable role.

Back in the 1980s, some Chinese researchers began to pay attention to the elderly re-employment problems. Some researchers have studied this problem from the perspective of "worthiness in old age". Cangping Wu (1986) proposed that as an issue of common concern in the world, ageing problem mainly including two main aspects: "be looked after in old age "and" worthiness in old age". After 2000, China entered the aging society, (Zhenwu Zhai, 2013), "be looked after in old age" get a lot of attention, "worthiness in old age" has been enriched and developed at the same time. Peng Du et al. (2011) believed that "worthiness in old age" including continued employment and re-employment, volunteering and family care when reach or over retirement age. 


\section{Urban Elderly Re-employment Current Situation and Problems}

\subsection{Urban Elderly Re-employment Current Situation}

(1) Overall Situation of Urban Elderly Re-employment

Table 1. Composition of Urban Elderly Re-employment by Age and Sex in 2003-2013(\%)

\begin{tabular}{|c|c|c|c|c|c|c|c|c|c|c|c|c|}
\hline \multicolumn{4}{|l|}{ Age } & \multicolumn{3}{|c|}{$55-59$} & \multicolumn{3}{|c|}{$60-64$} & \multicolumn{3}{|c|}{$65+$} \\
\hline Year & Total & $\begin{array}{l}\text { Male } \\
\text { Total }\end{array}$ & $\begin{array}{c}\text { Female } \\
\text { Total }\end{array}$ & Total & Male & Female & Total & Male & Female & Total & Male & Female \\
\hline 2003 & 5.5 & 7.1 & 3.3 & 3.3 & 4.3 & 1.9 & 1.2 & 1.5 & 0.8 & 1 & 1.3 & 0.6 \\
\hline 2004 & 5.8 & 7.5 & 3.6 & 3.7 & 4.9 & 2.2 & 1.2 & 1.5 & 0.8 & 0.9 & 1.1 & 0.6 \\
\hline 2005 & 7.6 & 9.3 & 5.5 & 4.3 & 5.2 & 3.1 & 1.8 & 2.2 & 1.4 & 1.5 & 1.9 & 1 \\
\hline 2006 & 8.7 & 10.3 & 6.8 & 4.8 & 5.8 & 3.6 & 2.1 & 2.4 & 1.8 & 1.8 & 2.1 & 1.4 \\
\hline 2007 & 9.6 & 11.3 & 7.8 & 5.4 & 6.4 & 4.2 & 2.3 & 2.6 & 2.1 & 1.9 & 2.3 & 1.5 \\
\hline 2008 & 10.6 & 12.1 & 8.8 & 5.9 & 7 & 4.6 & 2.5 & 2.7 & 2.3 & 2.2 & 2.4 & 1.9 \\
\hline 2009 & 11 & 12.7 & 8.9 & 6.2 & 7.3 & 4.8 & 2.6 & 2.9 & 2.3 & 2.2 & 2.5 & 1.8 \\
\hline 2010 & 8.2 & 9.7 & 6 & 5 & 6.1 & 3.5 & 1.9 & 2.1 & 1.5 & 1.3 & 1.5 & 1 \\
\hline 2011 & 8.3 & 9.7 & 6.3 & 4.9 & 6 & 3.3 & 2 & 2.2 & 1.7 & 1.4 & 1.5 & 1.3 \\
\hline 2012 & 9.1 & 10.6 & 7.3 & 5.2 & 6.3 & 3.8 & 2.3 & 2.5 & 2.1 & 1.6 & 1.8 & 1.4 \\
\hline
\end{tabular}

Data resource: Human Resources and Social Security, "China Population and Employment Statistics Yearbook", 2013

Table 1 reflects the proportion of elderly re-employment in the total employment from 2003 to 2012. Overall, the proportion had a significant fluctuation in this decade, the $11 \%$ in 2009 is the highest and the $5.5 \%$ in 2003 is the lowest. From 2003 to 2009 , the proportion of elderly re-employment was rising, but in 2010 this proportion suddenly dropped to $8.2 \%$, which is worthy of our attention. In addition, from the gender point of view, the proportion of older men in the total male employment shared the same fluctuations in the 10 years, the $12.7 \%$ in 2009 is the highest and the $7.1 \%$ in 2003 is the lowest. The employment of older women is similar, the highest in 2009 , reaching $8.9 \%$, the lowest in 2003 , accounting for only $3.3 \%$. Compared the elderly men and women, we can find that from 2003 to 2012, the proportion of men re-employment was always higher than women. This fact indicates that older men play a more important role in re-employment than women.

\section{(2) Distribution of Urban Elderly Re-employment Occupation}

Table 2. Composition of Urban Elderly Re-employment Occupation by Age and Sex in 2012(\%)

\begin{tabular}{|c|c|c|c|c|c|c|c|c|}
\hline $55-59$ & 100.0 & 3.9 & 10.3 & 12.3 & 22.5 & 30.3 & 20.1 & 0.7 \\
\hline $60-64$ & 100.0 & 2.1 & 5.8 & 6.0 & 20.3 & 51.0 & 14.1 & 0.7 \\
\hline Male & 100.0 & 4.6 & 13.2 & 11.9 & 25.4 & 12.0 & 32.4 & 0.5 \\
\hline $55-59$ & 100.0 & 5.2 & 11.4 & 16.2 & 20.6 & 21.1 & 24.7 & 0.8 \\
\hline $60-64$ & 100.0 & 2.9 & 7.0 & 8.9 & 18.9 & 42.8 & 18.9 & 0.7 \\
\hline $65+$ & 100.0 & 1.1 & 4.7 & 6.3 & 16.8 & 61.7 & 9.1 & 0.3 \\
\hline $65+$ & 100.0 & 0.3 & 2.1 & 0.8 & 12.8 & 79.1 & 4.4 & 0.5 \\
\hline
\end{tabular}

Data resource: Human Resources and Social Security, "China Population and Employment Statistics Yearbook", 2013 
From the type of elderly re-employment point of view, the majority of older people were engaged in agriculture after retirement, the proportion of the three age groups were $30.3 \%, 51 \%, 68.2 \%$. The second choice was engaged in business services, the proportion of the three age groups were $22.5 \%, 20.3 \%, 15.3 \%$. The third choice was worked as the equipment operators of production or transport equipment, the proportion were $20.1 \%, 14.1 \%, 7.3 \%$. However, the proportion of other re-employment types was very low, but it's worth noting that as an unite head or specialist, the proportion of lower age group was significantly higher than older age groups, therefore in technical work, the low-aged group has more advantage. In addition, from the gender point of view, despite the proportion of the older men and women who were engaged in the production category was the largest, but there's significant difference. In the types of unite head, specialist, clerk and equipment operators, the proportion of three age groups of men were significantly higher than women. Obviously, more retired men tend to engage management or technical work, while women tend to the work which demand for less technical or management capacity.

\subsection{Urban Elderly Re-employment Problems}

\section{(1) The lack of the elderly re-employment protection laws}

Although China has enacted relevant laws to protect the rights of older people, but it has not yet introduced special laws to solve the problems about the right and form disputes happened in the process of elderly re-employment, which makes the older people lack of legal protection when they meet labor disputes or legitimate rights are infringed upon. Moreover, although the relevant legislation has clearly defined the rights that older people enjoy, but there is no clear division in charge of these issues, thus if there are problems in elderly re-employment, because of the unclear departments, it's difficult to solve their problems. Both of these two reasons make re-employment enthusiasm of the older people greatly reduced.

\section{(2) Elderly human resource has a low quality}

2010 sixth national census data showed that in the elderly population, the largest proportion of the cases was illiteracy, representing $35.82 \%$, next was the case of primary school education, accounting for $32.14 \%$, then the junior high school seniors, accounting for $14.63 \%$, the case of college and other higher education was only $4.74 \%$. In addition, the education level of the younger age group is relatively higher than the older age group, that is the younger age group of the elderly has higher level of human capital. The distribution of human resources has greatly limited the choices of elderly re-employment, most of the older people can only choose the manual work that requires less technical, only a handful of younger and better-educated older people is competent to technical or management work.

\section{Urban Elderly Re-employment Countermeasures}

\subsection{Complete the Policies and Regulations for Elderly Re-employment}

Although the elderly re-employment has been advocate congruously, because of the lack of policies and regulations, the reemploy equity of the elderly is little protected. Therefore, the government should develop more comprehensive re-employment policies and regulations for the elderly, such as workable fiscal policies, delaying the retirement age policy and appropriate pension, health care and other social security policies and so on. Aiming at social needs, it may be encouraged to exert the expertise and function of the elderly that the elderly voluntarily provide consulting services, participate in business and production activities. Thus the equity of the elderly re-employment can be protected effectively.

\subsection{Improve the Quality of Elderly Population}

Although China currently has a very rich elderly human resource, and there are a lot of elderly people with high-quality, high-skills, but there are still a considerable number of elderly people who has low educational level. Therefore, the elderly should be encouraged to accept various forms of continuing education, learn professional knowledge and skills. Specifically, first, increase work skills trains to young healthy elderly, improve their ability to re-employment; second, raise the cultural level of the elderly by providing cultural education; third, the elderly university should offer some courses required for the elderly, to rich their spiritual and cultural life.

\section{Conclusion}

The future labor supply shortage problems posed by the rapid population aging had a greatly huge impact for the sustainable development of China's economic. The elderly re-employment is an important way to deal with the aging population and ease the labor shortage problem in China. However, while China has very rich elderly human resource, but the elderly still suffered low level of education and the lack of protection policies, which seriously restricts the range of options of elderly re-employment. Combined with our own population social characteristics, this paper raised some urban elderly re-employment countermeasures, hoping to respond effectively to China's aging population, to promote social and economic stability, speed development.

\section{Acknowledgments}

The work was financially supported by National Social 
Science Fund of China (14BRK003), the science and technology support program of Hubei Province (2014BDF063).

\section{REFERENCES}

[1] Guangzong Mu, Tuan Zhang. China's aging population trends and the strategic response[J]. Learned Journal of Central China Normal University, 2011(5):29-36.

[2] Yuan Ren, Implement productive aging strategy, developing the elderly human resources[J]. China Society,2013.3.1
[3] Leland Natalie E, Elliott Sharon J. Special issue on productive aging: Evidence and opportunities for occupational therapy practitioners $[\mathrm{J}]$. American Journal of Occupational Therapy, 2012, 66(3): 263-265.

[4] Cangping Wu, Haibo Qu. Preparation for the challenges of population aging $[\mathrm{J}]$. Journal of Chinese Gerontology,1986(4):3-5.

[5] Zhenwu Zhai. Construction of balanced population societ[J]. Seeking, 2013(23):57-59.

[6] Peng Du. Delay retirement age to deal with the aging population[J]. Population and Development, 2011(4):26-30. 